\title{
An Integrative Regional Resilience Framework for the Changing Urban Water Paradigm
}

\section{Authors:}

Patricia Gonzales ${ }^{1,2}$, corresponding author

Email: patgonza@stanford.edu

Present address: 473 Via Ortega, Room 204, Stanford, California 94305, United States

\section{Newsha K. Ajami ${ }^{2,3}$}

Email: newsha@stanford.edu

Present address: 473 Via Ortega, Room 204, Stanford, California 94305, United States

[1] Department of Civil and Environmental Engineering, Stanford University.

473 Via Ortega, Room 314, Stanford, California 94305, United States

[2] ReNUWIt Engineering Research Center, Stanford University.

473 Via Ortega, Room 117, Stanford, California 94305, United States

[3] Woods Institute for the Environment, Stanford University.

473 Via Ortega, Room 204, Stanford, California 94305, United States 


\section{Abstract}

The water sector is going through a paradigm shift. Many communities are incorporating decentralized solutions such as water reuse and recycling, stormwater capture, and demand-side management in order to address both short-term and longterm water resources challenges due to population increase, economic growth, intensified climate variability, as well as environmental concerns. For these projects to be sustainable, local characteristics including social and institutional contexts must be incorporated in the planning process. This paper presents a flexible and bottom-up framework that facilitates integration of such characteristics in evaluation of various water resource management strategies. It incorporates various locally-driven factors such as water use efficiency, stress on existing supplies, and adaptation capacity potential, to identify how various local and regional solutions affect resiliency at the utility and regional levels. Rather than defining top-down resilience standards, this framework incorporates quantitative and qualitative assessments that can help decisionmakers tailor adaptation measures to the needs and opportunities of a given location or community. A case study application of the framework in the San Francisco Bay Area highlights how community-level characteristics can be used to identify opportunities and adaptation strategies in order to enhance both local and collective water resource resiliency.

\section{Keywords}

Urban water; regional water management; resilience; water supplies; water demand; supply diversity 


\section{Introduction}

The past few decades have seen changes in the scope and focus of urban water management in many parts of the world [Hering et. al., 2013]. Traditional urban water systems were built as a combination of independent components and managed by multiple governing agencies, typically comprising extensive distribution pipelines to bring water into cities, centralized treatment plants, and disposal systems for moving wastewater and stormwater away from urban centers. In many urban areas, where climate variability, growing populations, and degrading ecosystems are prominent, it is now evident that this traditional paradigm will not be suitable to meet future challenges [Chartres and Williams, 2006; Hering et. al., 2013; Padowski and Gorelick, 2014; Viviroli et. al., 2011]. There is increasing awareness that over-reliance on imported supplies places undue stress on supply sources that are themselves sensitive to seasonal precipitation changes, periodic droughts and infrastructure degradation [Brozovic et al., 2007; Cayan et al., 2010; Diffenbaugh et al., 2015; Viviroli et al., 2011]. Furthermore, the fragmented nature of today's water management institutions translates into a disconnect between local priorities, environmental concerns, and regional water resources that know no political boundaries [Graymore et. al., 2010; Hering et. al., 2013; Hughes and Pincetl, 2014; Kauffman, 2002; Padowski and Jawitz, 2009].

In response to the growing water insecurity, especially in arid and semi-arid regions such as Australia, Israel, and the Western United States, there has been increasing interest in alternative practices including water recycling and reuse [Arlosoroff, 2007], stormwater capture, desalination, water efficiency and conservation measures [Hornberger et. al., 2015; Mini et. al., 2015], and combinations of these 
options [Beh et. al., 2014; Luthy, 2015; Newman et. al., 2014; Srinivasan et. al., 2010; Tarroja et. al., 2014]. The adoption of these alternative supplies has been accompanied by innovative and adaptive governance configurations in the search for more reliable and resilient systems that can withstand variable and uncertain conditions [Beh et. al., 2015; Connel-Buck et. al., 2011; Ferguson et. al., 2013; Hughes et. al., 2013; Nelson et. al., 2008; Paton et. al., 2014; Rijke, 2013; Tal, 2006]. Despite emerging initiatives, there are still many financial, political, and institutional barriers to the widespread adoption of more reliable and resilient urban water supplies [Brown and Farrelly, 2009; Hughes, 2013; Moglia et. al., 2011; Winz et. al., 2014]. As the water use cycle evolves, existing tools for the assessment, planning and management of urban water systems need to be re-designed to support a more holistic evaluation of the combination of supply diversification options, system-wide dynamics, and intra-regional collaboration called for by the current paradigm shift in urban water management.

Numerous metrics and assessments that have been developed in the past can provide a robust backbone to enable such a systems-level perspective [Brown et. al., 2015; Juwana et. al., 2012; Marlow et. al., 2013; Padowski et. al., 2015]. For example, the popular metrics of reliability, resiliency, and vulnerability [Hashimoto et. al., 1982; Loucks, 1997] provide an understanding of various components of our water supply systems at various scales, such as regional hydrologic flows [Ajami et. al., 2008; Sandoval-Solis et. al., 2011], and local distribution systems [Aydin et. al., 2015; Li and Lence, 2007]. These and other metrics have been applied in comprehensive assessments of the resilience of existing systems when faced with the uncertainties of a range of future scenarios [Milman and Short, 2008; Sullivan et. al., 2006; Sandoval- 
Solis et. al., 2011]. However, these assessments typically focus on how robust the engineered or natural systems are with respect to pre-defined standards, rather than their capacity to be adapted in response to changing needs and priorities of multiple water actors and uses. Overall, while previous approaches have developed useful tools for the analysis of their respective study goals, they have been tailored to the needs of the conventional water management perspective, focused on supply-side infrastructure and centralized top-down objectives. For example, despite the growing emphasis on supply diversification as a means to achieve increased reliability and resilience, there is currently no guidance on what constitutes a diverse water supply portfolio, or how this measure can be used as a guideline to enhance regional resiliency. There is a need for more flexible frameworks that can help identify bottom-up resiliency strategies based on local needs and opportunities, as well as the potential for collaborative approaches.

In this paper we present a novel resilience framework that builds upon previous assessments with two new and significant contributions designed for the emerging challenges in the urban water sector: (1) a focus on the added flexibility that decentralized approaches can provide to urban water systems; and (2) a bottom-up measure that integrates the local socio-hydrologic realities of water service providers and assesses their role on regional-scale resilience. Thus, rather than attempt to define top-down resilience standards for a region and arbitrary numerical goals to pursue, our systematic framework helps identify strategies that suit each community's needs and opportunities which can ultimately improve overall regional resiliency. We follow qualitative and quantitative indicators related to three pillars: supply, demand, and adaptation capacity,. We demonstrate the application of this framework to a subset of 
water utilities in the San Francisco Bay Area of California, who have recently been under significant pressure to implement reliability and resilience measures in the face of a historical drought. The urban water service providers in this case study are interconnected not only by hydrologic systems, but also by a representative coordinating agent: the Bay Area Water Supply and Conservation Agency.

\section{Methods}

\subsection{Conceptual framework}

The resilience framework developed in this study integrates a qualitative and quantitative screening of an urban water system's capacity to prepare and adapt to potential stressors based on: the reliability of existing supply portfolios, the capacity to implement demand-side management, and the potential impacts of adaptation strategies on both supply and demand (Figure 1). The framework consists of (1) defining indicators and metrics relevant to a given region's goals and realities, which are subsequently (2) aggregated into a single resilience index. This is followed by (3) an evaluation of the local and regional characteristics driving the performance metrics of water service providers. Finally, (4) we perform a comparative assessment of what these metrics tell us about urban water reliability and resilience at the local and regional scales. This systematic bottom-up approach provides a comparative platform for utilities to identify their relative strengths and weaknesses with respect to different metrics of interest, while highlighting opportunities for collaborative management in the implementation of adaptation strategies that are feasible and practical in context. 


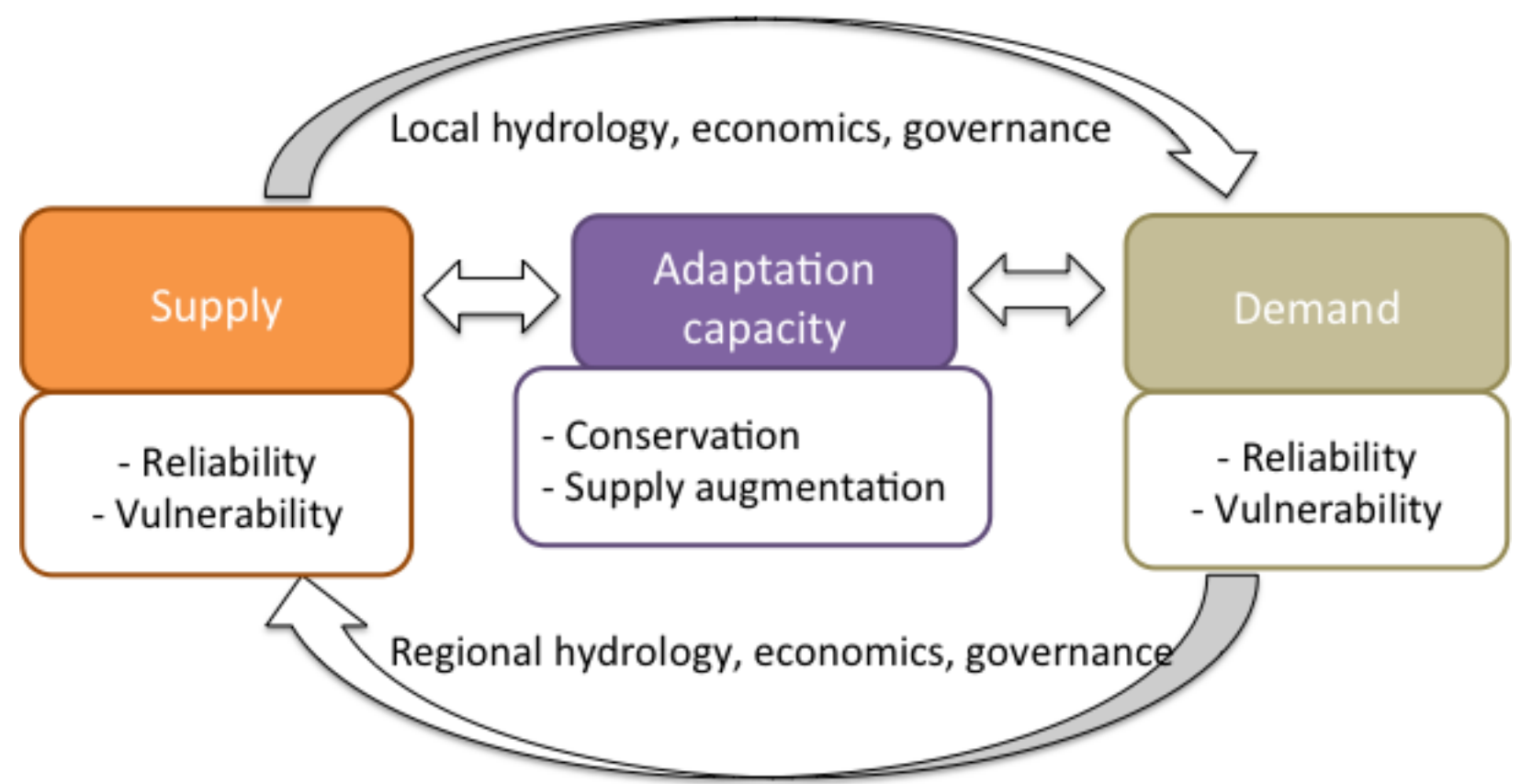

Figure 1. Resilience framework for urban water systems, based on the assessment of supply, demand, and adaptation capacity.

\subsection{Identification of metrics and assumptions}

Water resource systems are defined not only based on the layout and historic flows of hydrologic systems, but also as a function of political decisions, collaborative agreements, and inter-dependencies among water providers [Padowski et. al., 2015]. Consequently, it is important to identify resilience factors on a region-by-region basis considering on-the-ground realities. Table 1 highlights some baseline metrics related to pre-defined themes. The use of metrics in this framework is intended to provide perspective on the relative performance of water service providers with respect to their priorities at any given time. Thus, metrics should be selected to reflect the most pressing aspects affecting water supply and demand dynamics in a region of study, and used as a moving target aligned with the utility's areas of interest and opportunities as they move forward in their water reliability and resiliency enhancement efforts. Similarly, 
the possible range of each metric is defined based on relative performance, and utilities are encouraged to improve their performance within those ranges, particularly the ones with lower performance values. As utilities make progress, the expectations for performance, and thus the range of values for metrics, can be adjusted to become increasingly stringent.

Table 1. Baseline metrics applied to quantitative resilience analysis

\begin{tabular}{ccc}
\hline Theme & Indicator & Example metrics \\
\hline Supply & Supply stress & Proportion of available supplies currently being used \\
& Water quality level \\
Supply diversity & Gini-Simpson index \\
\hline \multirow{2}{*}{ Demand } & $\begin{array}{c}\text { Water use } \\
\text { efficiency } \\
\text { Demand diversity }\end{array}$ & Water use per capita in different sectors \\
\hline \multirow{2}{*}{$\begin{array}{c}\text { Adaptation } \\
\text { capacity }\end{array}$} & $\begin{array}{c}\text { Conservation } \\
\text { capacity } \\
\text { Augmentation } \\
\text { capacity }\end{array}$ & Projected water savings from conservation measures \\
\hline
\end{tabular}

Most of the metrics proposed in this baseline framework have been defined in the literature or are commonly used in practice for urban water planning and management assessments [Juwana et. al., 2012; Loucks, 1997]. The exception is the quantification of the diversity of water supply and demand portfolios, which, as pointed out in the introduction, has not been yet defined or measured in the water sector. Water supply diversity is an important indicator of reliability and resilience because it demonstrates how flexible a supply portfolio is, or the capacity to shift between supply sources if any particular source becomes compromised. Similarly, demand diversity indicates flexibility 
in terms of the capacity of a system to incorporate tailored water supplies to meet the different water quality needs of different users, reducing stress on existing high-quality sources. In this analysis we use the Gini-Simpson index [Simpson, 1949], a measure commonly used in biodiversity, sociology, psychology, economics, and information science [Gibbs and Martin, 1962; Humprecht, 2013; McDonald, 2003; Oksanen, 2015; Panniello, 2014; van Beers, 2014] as an indication of the number of different types (e.g. species, industries, water sources) ( $n$ ) and their relative abundance (computed as the fraction of the total, ranging between 0 and 1) (p) (Eq. 1). Mathematically, the GiniSimpson index indicates the probability that two entities taken at random from a dataset of interest represent different types [Hurlbert, 1971], and thus it ranges from 0 (a single type present) to 1 (highly diversified portfolio). While other tools are available that reflect similar measures (e.g. Simpson index, Shannon index, etc.), these have been found to be generally interchangeable for simple analyses [Morris et. al., 2014], with the GiniSimpson version being one of the most popular in the literature. We choose to use the Gini-Simpson index in this framework for its popularity in multiple fields, simple form, easiness of quantification, and intuitive scale.

Gini-Simpson index $=1-\sum_{i=1}^{n} p_{i}^{2}$

\subsection{Re-scaling and integration of metrics}

We develop an aggregate resilience index incorporating the quantitative metrics of interest into a single number for easier comparison within a region, building upon mathematical principles from numerical indices in the literature [Ajami et al., 2008; 
Juwana et al., 2012; Loucks, 2005; Sandoval-Solis et al., 2011]. For this purpose, we normalize metrics by linearly re-scaling them from their observed $A-B$ range to a 1-10 range (Eq. 2), where $A$ and $B$ are the lower and upper bound of the original scale, respectively. In the resulting 1-10 range, each indicator retains its intuitive scale. For example, higher values for supply diversity are associated with increased contributions to resilience, whereas higher values for supply stress have a negative connotation. It is important to notice that this is a comparative index, and should be used as a moving target rather a goal of achieving a certain score. This relative nature means that no single number should be used as a global standard, and is more suited to the bottom-up needs of evolving water suppliers who are all starting from a different reference point, and who may be pursuing different goals.

Re - scaled I $=1+(10-1) * \frac{(\mathrm{I}-\mathrm{A})}{(\mathrm{B}-\mathrm{A})}$

The re-scaled indicators are then aggregated into their respective theme of supply (S) or demand (D) (Eq. 3-4), and the two theme components are subsequently aggregated into an overall resilience index (Eq. 5), using the geometric mean. When aggregating values, negative indicators are linearly transformed to the opposite end of the scale in order to follow the normalized 1-10 range. For example, in Eq. 3-4, the values for supply stress and water use are subtracted from 11 (the sum of lower and upper values of the re-scaled range), such that the highest observed value (10) corresponds to the lowest resilience performance (1) and vice versa, similar to what 
previous authors have done with vulnerability metrics [Ajami et al., 2008; Juwana et al., 2012; Loucks, 2005; Sandoval-Solis et al., 2011].

We compute the resilience index with and without adaptation capacity measures to assess their potential effect on supply and demand indicators. For example, introducing conservation potential would decrease water use, decrease the percentage of allocations being used, and potentially shift supply and demand diversity. This comparative assessment allows us to identify what the most effective adaptation strategies are, and which indicators of interest have the most flexibility to be improved.

$\mathrm{S}_{\mathrm{i}}=\left[\left(11-\text { supply }_{\text {stress }}\right) *\left(\text { supply diversity }_{i}\right)\right]^{1 / 2}$

$\mathrm{D}_{\mathrm{i}}=\left[\left(11-\text { water }_{\text {use }}\right) *\left(\text { demand diversity }_{i}\right)\right]^{1 / 2}$

Local resilience $\mathrm{i}_{\mathrm{i}}=\left[\left(S_{i}\right) *\left(D_{i}\right)\right]^{1 / 2}$

Our index is calculated using the geometric mean to address the challenge of assigning specific weights to each criterion. This approach has previously been proposed for water resources management [Ajami et al., 2008; Loucks, 1997; SandovalSolis et al., 2011]. The multiplicative form of the geometric mean allows us to normalize the ranges of performance values being averaged, such that a very large performance value can't negate or substitute smaller values [Juwana et al., 2012]. This form also allows the index to be easily adapted to different contexts, since additional indicators may be added or re-defined within the supply and demand components before being integrated into the overall index. 
Finally, to identify the impact of local performance on the regional scale, we propose a weighted average of resilience indices (Eq. 6), where weights correspond to the fraction of the total regional demand $(D)$ that is attributed to a utility's individual demand $\left(d_{i}\right)$.

Regional resilience $=\sum_{\mathrm{i}} \frac{\mathrm{d}_{\mathrm{i}}}{\mathrm{D}} *\left(\right.$ Local resilience $\left._{\mathrm{i}}\right)$

\section{Results and discussion}

\subsection{Study Region: Bay Area Water Supply and Conservation Agency}

To demonstrate the practical application of our resilience framework, we apply our methodology to a case study in the San Francisco Bay Area. Specifically, we focus on the Bay Area Water Supply and Conservation Agency (BAWSCA), a coordinating agency representing the needs of 26 water utilities that are dependent on the San Francisco Regional Water System (SF RWS) (Figure 2). This region provides a good study site for our framework because it encompasses several water utilities that are autonomous and unique, yet are highly reliant on a common pool of imported and local water supplies, and who have the capacity to participate in coordinated regional efforts through BAWSCA. Furthermore, California, as the most populated state in the United States and with variable precipitation patterns and unevenly distributed water supplies, faces the need to address the long-term reliability of its state-wide urban water resources [CDWR, 2015; CDWR, 2013; Grantham and Viers, 2014]. The state is currently in its fifth year of a historical drought that has left many urban water systems vulnerable and in search of innovative resiliency solutions. 
BAWSCA's 26 member agencies serve 1.8 million residents, businesses, and community organizations representing a diverse group of service areas. For example, based on data from fiscal year 2014-15 (July 2014 to June 2015) [BAWSCA, 2015], population size and water use per capita span the range of 4,282 - 344,000 people and 53.9 - 324.2 gallons per capita per day, while the average price of water and median household income vary between 0.41 - 1.16 cents per gallon and $\$ 50,142$ - $\$ 236,528$ per year, respectively. BAWSCA has the authority to coordinate water conservation, supply and recycling activities for its member agencies, acquire water supplies, finance projects, and build facilities.

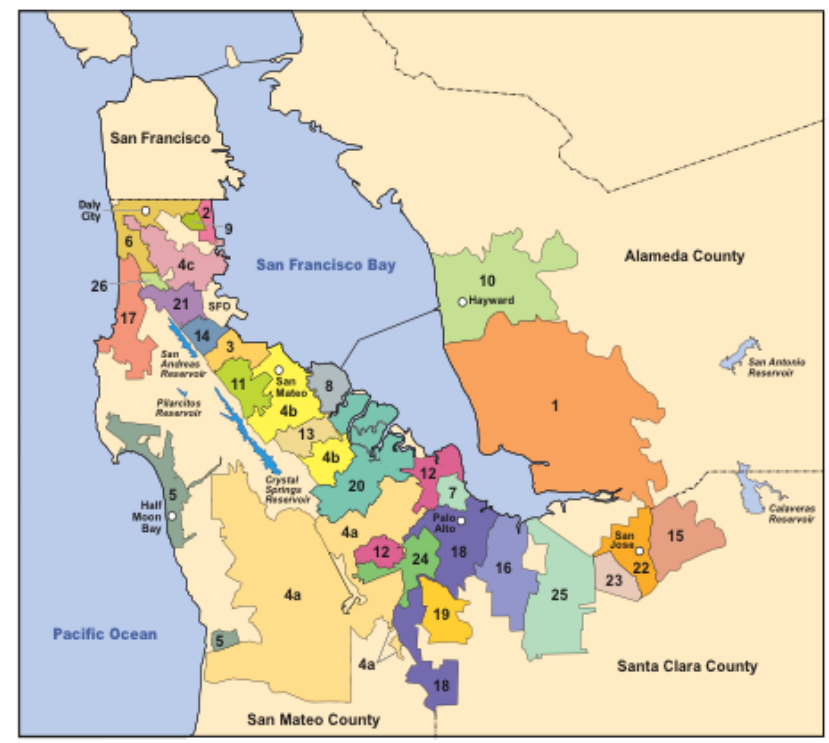

$\begin{array}{ll}\text { Legend } & \\ 1 \text { Alameda County Water District } & \mathbf{1 3} \text { Mid-Peninsula Water District } \\ \mathbf{2} \text { City of Brisbane } & \mathbf{1 4} \text { City of Millbrae } \\ \mathbf{3} \text { City of Burlingame } & \mathbf{1 5} \text { City of Milpitas } \\ \mathbf{4 a} \text { CWS- Bear Gulch } & \mathbf{1 6} \text { City of Mountain View } \\ \mathbf{4 b} \text { CWS- Mid-Peninsula } & \mathbf{1 7} \text { North Coast County Water District } \\ \mathbf{4 c} \text { CWS- South San Francisco } & \mathbf{1 8} \text { City of Palo Alto } \\ \mathbf{5} \text { Coastside County Water District } & \mathbf{1 9} \text { Purissima Hills Water District } \\ \mathbf{6} \text { City of Daly City } & \mathbf{2 0} \text { City of Redwood City } \\ \mathbf{7} \text { City of East Palo Alto } & \mathbf{2 1} \text { City of San Bruno } \\ \mathbf{8} \text { Estero Municipal Improvement } & \mathbf{2 2} \text { San Jose Municipal Water System- } \\ \text { District } & \text { North } \\ \mathbf{9} \text { Guadalupe Valley MID } & \mathbf{2 3} \text { City of Santa Clara } \\ \mathbf{1 0} \text { City of Hayward } & \mathbf{2 4} \text { Stanford University } \\ \mathbf{1 1} \text { Town of Hillsborough } & \mathbf{2 5} \text { City of Sunnyvale } \\ \mathbf{1 2} \text { City of Menlo Park } & \mathbf{2 6} \text { Westborough Water District } \\ \end{array}$

Figure 2. BAWSCA members map. Source: BAWSCA Annual Survey for Fiscal Year 2014-15

\subsection{Resilience indicators in BAWSCA}

To better understand how the socio-hydrologic dynamics of the diverse communities in BAWSCA interact in the transition towards a more reliable and resilient regional water system, we applied our integrative resilience framework. Table 2 defines 
the metrics and assumptions used in this case study, adapted from the baseline resilience framework methodology (Table 1). For this application, the metrics related to supply stress are focused on water use from the major water supply in the region: the SF RWS. This water system is dependent on pristine snowmelt from the Sierra Nevada Mountains, and requires little treatment before going to people's homes. Water quality mostly is not a concern in the system and is thus excluded from our case study application of the framework. Similarly, we adapt the water use efficiency indicator to focus on water demand in the residential sector as an even platform for comparison. A more detailed description of the importance of each indicator selected, and its relevance to local and regional resilience assessments is discussed in the following sub-sections.

Table 2. Assumptions for quantitative metrics used in BAWSCA resilience assessment.

\begin{tabular}{|c|c|c|c|c|}
\hline Theme & Indicator & Metrics and assumptions & $\begin{array}{l}\text { Original } \\
\text { range }\end{array}$ & $\begin{array}{l}\text { Re-scaled } \\
\text { range }\end{array}$ \\
\hline \multirow[b]{2}{*}{ Supply } & Supply stress & $\begin{array}{l}\text { Fraction of allocations from the SF RWS } \\
\text { currently being used }\end{array}$ & $0.1-1.62^{a}$ & $1-10$ \\
\hline & $\begin{array}{l}\text { Supply } \\
\text { diversity }\end{array}$ & $\begin{array}{l}\text { Gini-Simpson index: } \\
1-\sum_{i}\left(\frac{\text { supply from source }}{\text { total supply }}\right)^{2}\end{array}$ & $0-0.9$ & $1-10$ \\
\hline \multirow{2}{*}{ Demand } & Water use & $\begin{array}{l}\text { Water demand per capita in the residential } \\
\text { sector }\end{array}$ & $\begin{array}{l}20-340 \\
\text { gallons per } \\
\text { capita per day }\end{array}$ & $1-10$ \\
\hline & $\begin{array}{l}\text { Demand } \\
\text { diversity }\end{array}$ & $\begin{array}{l}\text { Gini-Simpson index: } \\
1-\sum_{i}\left(\frac{\text { demand from sector }}{\text { total demand }}\right)^{2}\end{array}$ & $0-0.9$ & $1-10$ \\
\hline \multirow{2}{*}{$\begin{array}{l}\text { Adaptation } \\
\text { capacity }\end{array}$} & $\begin{array}{l}\text { Conservation } \\
\text { capacity }\end{array}$ & $\begin{array}{l}\text { Projections of the potential savings } \\
\text { achievable through conservation and water } \\
\text { use efficiency measures, computed as a } \\
\text { fraction of total demand }{ }^{b}\end{array}$ & $0-0.3$ & $\begin{array}{l}\text { (computed into } \\
\text { supply and } \\
\text { demand } \\
\text { indicators) }\end{array}$ \\
\hline & $\begin{array}{l}\text { Augmentation } \\
\text { capacity }\end{array}$ & $\begin{array}{l}\text { Fraction of total demand that may be } \\
\text { satisfied by feasible alternative supplies }{ }^{c}\end{array}$ & $0-0.3$ & $\begin{array}{l}\text { (computed into } \\
\text { supply and } \\
\text { demand } \\
\text { indicators) }\end{array}$ \\
\hline
\end{tabular}

${ }^{a}$ The fraction of allocations being used extends beyond 1 because some agencies have historically purchased more water that their contracted allocated amounts. This is allowed when supplies are available in excess of the total demands from BAWSCA utilities. 
${ }^{\mathrm{b}}$ Projected water savings from feasible demand management programs to be implemented by 2040. Data taken from BAWSCA's Regional Demand and Conservation Projections report [BAWSCA, 2014].

${ }^{\mathrm{C}}$ Projected yield of feasible supply augmentation projects currently under consideration by BAWSCA. Data taken from BAWSCA's Long-Term Reliable Water Supply Strategy report [BAWSCA, 2015b]. Local projects identified by agencies comprise several recycled water projects and a groundwater project. Regional projects include local capture and reuse of rainwater, greywater, and stormwater, desalination of bay water and brackish groundwater, and water transfers.

The results of quantifying these relevant metrics for each BAWSCA agency are shown in Figure 3, based on data reported in the 2014-15 BAWSCA Annual Survey [BAWSCA, 2015a]. Each indicator in the graph reflects re-scaled values according to Eq. 2. The results show that overall, the strongest performance for most BAWSCA utilities is related to low per capita water demand, while the weakest performance is related to low diversity of supply portfolios. Furthermore, the adaptation capacity indicators show that most utilities still envision a high capacity to expand their conservation programs, and a few utilities are also planning to incorporate additional augmentation projects that could provide them considerable local resilience benefits. Analyzing each individual indicator allows us to see that BAWSCA member agencies have several opportunities to enhance the reliability and resilience of their water supplies. 


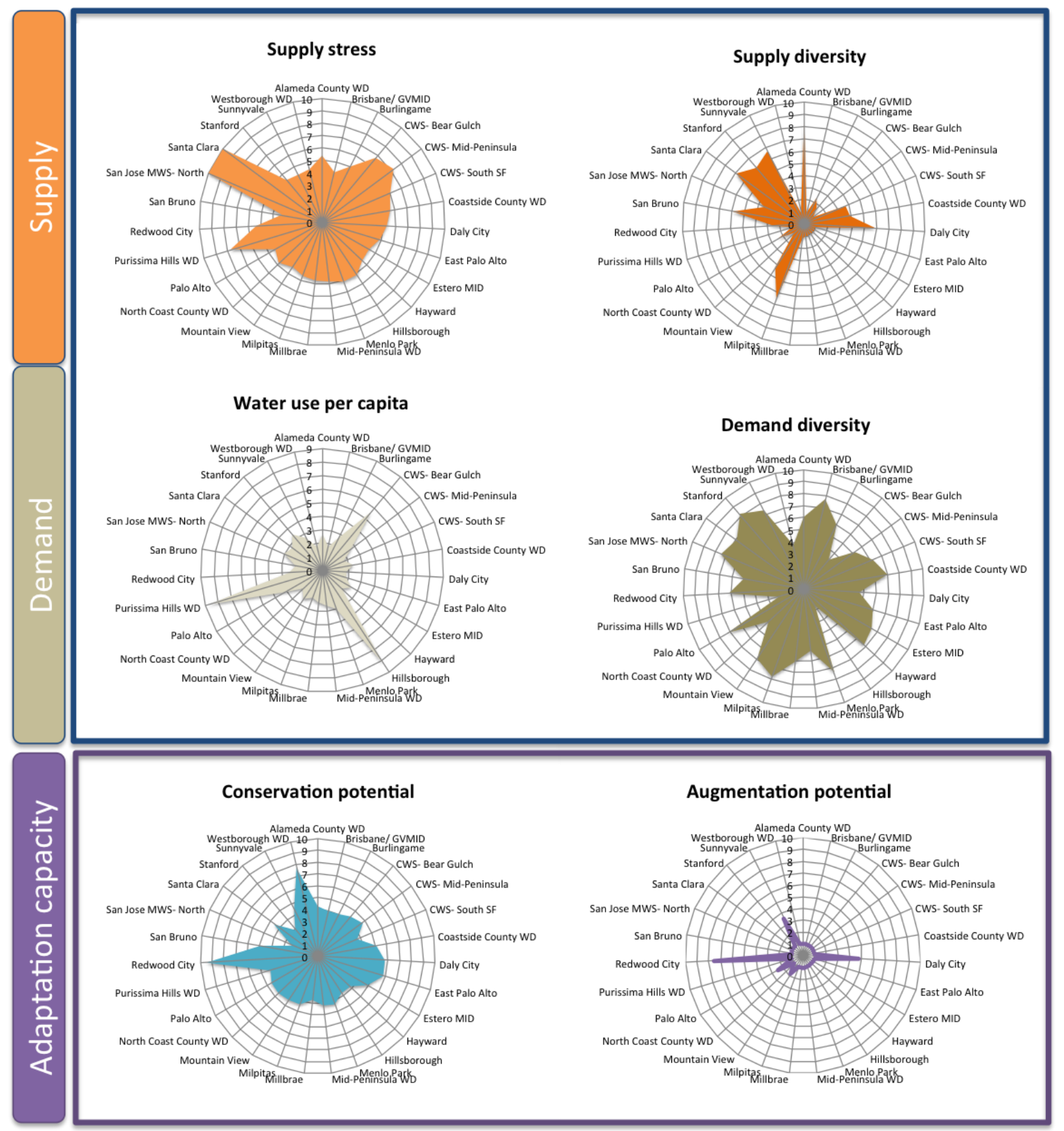

3 Figure 3. Resilience indicators and metrics computed for each BAWSCA member agency as of fiscal year 2014-15. Numbers are already scaled such that higher values reflect better performance with respect to the baseline (see Table 2).

\subsubsection{Supply stress}


To understand the stress on BAWSCA water supplies, it is important to understand not only the hydrology but also the governance dynamics of the region's main water source: the SF RWS. Each BAWSCA member agency is subject to an individual water sales contract from the SF RWS, which specifies an Individual Supply Guarantee (ISG) for that agency. The permanent ISGs (Figure 4) were agreed to and adopted by the governing bodies of all of SFPUC's permanent wholesale customers in 1994 and reflected the conditions and known projections at the time, but they may not be adequate for present conditions, and water deliveries are subject to cutbacks in times of shortage [BAWSCA, 2015]. For example, both Purissima Hills Water District and the city of Menlo Park are solely dependent on water from the SF RWS, but Purissima Hills is currently using up the entirety of its allocated supply, while Menlo Park's demand accounts only for $80 \%$ of their allocation, indicating Menlo Park could potentially be less vulnerable in their projections for future needs as shown by the difference in scores between the two agencies. Similarly, San Jose MWS and the city of Santa Clara don't have permanent contracts or an ISG, and thus show the highest supply stress in Figure 3. Currently, BAWSCA agencies are allowed to purchase water beyond their allocated ISG when supplies are available in the SF RWS, but water availabilities from the SF RWS could be impacted by competing demands, infrastructure damage, climate change and the ensuing hydrologic conditions, policy decisions, and regulatory actions [SFPUC, 2013]. 

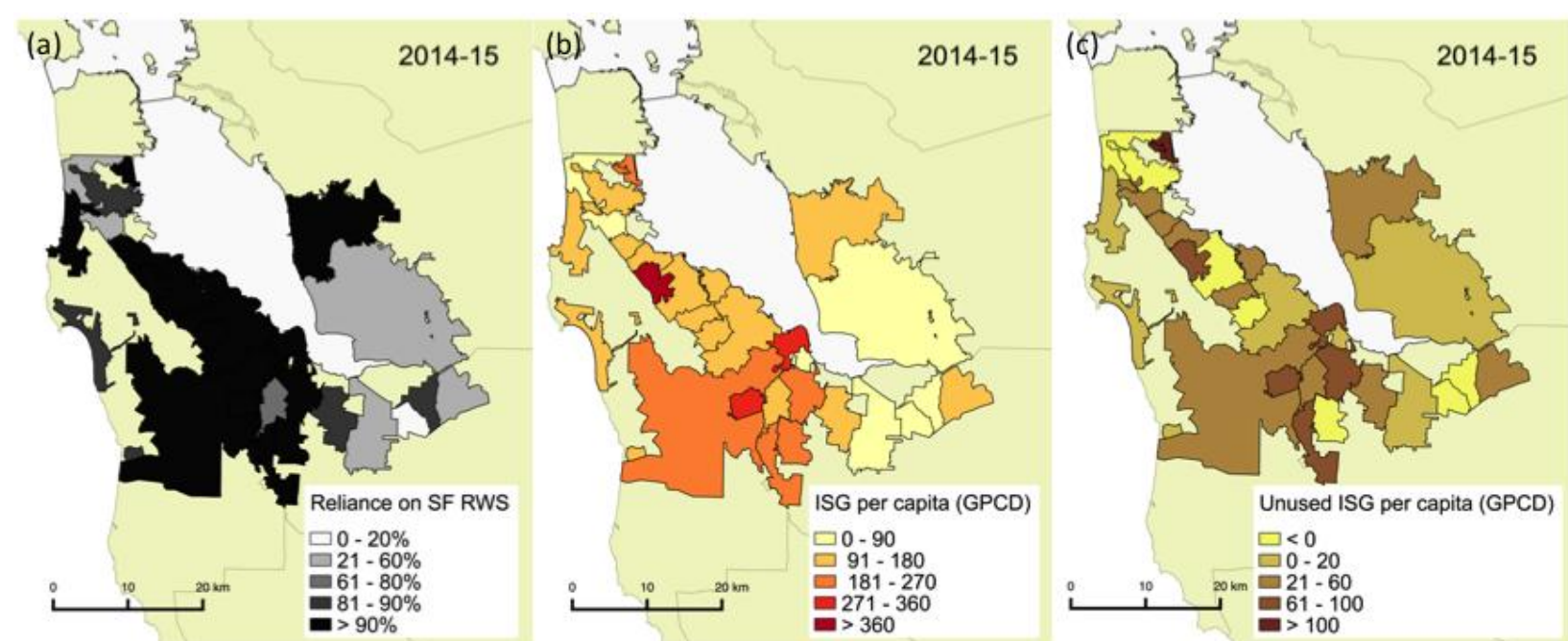

Figure 4. (a) Reliance on SF RWS as a percentage of total supplies, (b) distribution of individual supply guarantee among agencies, normalized by population, and (c) unused supplies (individual supply guarantee minus actual water purchases) normalized by population. Data as of fiscal year 2014-15.

\subsubsection{Supply diversity}

Overall, two thirds of BAWSCA agencies' water supplies come from SF RWS.

While some utilities rely solely on the SF RWS, others have strategically diversified their water supply portfolios to include additional sources such as groundwater, local surface water, recycled water, and imported water from the State Water Project and Central Valley Project. However, it is important to note how this diversity is distributed among BAWSCA agencies. Although several of the larger water agencies (Alameda County Water District, Santa Clara, Milpitas, Sunnyvale, and Daly City) have diverse water supplies (reflected in high scores in Figure 3), most service areas in our study region have a small enough demand that their imported SF RWS supply is sufficient to cover their present needs and growth projections. This lessens the sense of urgency for these utilities to collaborate or develop alternative supplies. Nevertheless, on an agency-byagency basis, the long-term reliability of BAWSCA's traditional supply portfolios is highly uncertain [BAWSCA, 2015b]. The need to diversify water supply portfolios is 
exacerbated by the potential economic consequences of supply shortfalls. Economic losses to businesses and residential users under a $20 \%$ water supply deficiency on the SF RWS are estimated up to $\$ 7.7$ billion annually [BAWSCA, 2015b]. This number could almost double under a supply interruption scenario in the RWS such as an earthquake, with economic loss estimates of up to $\$ 14$ billion in damage costs depending on the extent and location of the disruption [Brozovic et al., 2007; Khater, 1993]. Based on the potential risks of future shortages, even if BAWSCA member agencies have not outgrown their allocated supplies from the SF RWS, they could considerably enhance their reliability and resilience by diversifying their water supply portfolios.

\subsubsection{Water use}

Demand-side characteristics influence the reliability and resilience of water supplies. Water demand is a result of intrinsic water use behaviors in a community, as well as a function of land use, population density, industrial activities, outdoor irrigation needs, etc. [Hornberger et al., 2015; Mini et al., 2014; Panagopoulos, 2014]. Managing water demands effectively by taking into account these local characteristics can extend availability of water supplies and limit the potential impacts of water shortage, even when the reliability of the supplies themselves is uncertain.

Utilities in the BAWSCA service area have maintained a steady water demand for the past two decades thanks to investments on conservation and efficiency measures, which have provided some added resiliency to population growth and drought in the region [BAWSCA, 2014]. However, water use among some of these 
agencies may not be sustainable in the long-term. For example, Purissima Hills Water District, the Town of Hillsborough, and California Water Service- Bear Gulch, some of the higher income communities in the region, still have demands that exceed 150 gallons per capita per day (reflected in high water use scores in Figure 3). This may be in part because, even though BAWSCA-agency retail water prices have increased by $58 \%$ from 2005 to 2013 [BAWSCA, 2014], water bills are still only a small percentage of household income (less than 1\% for the majority of BAWSCA agencies), and therefore many consumers may not be properly aware of the true value of water in times of shortage [Pacific Institute, 2013]. As shown in Figure 5, there is a strong relationship between household income and water use in the BAWSCA region (R-squared $=0.83$ ), which overshadows the correlation between water use and other drivers of demand such as population density $(R$-squared $=0.25)$ and the price of water $(R$-squared $=$ 0.10). Structuring water rates, water use efficiency policies, and conservation incentives that take into account each service area's diverse characteristics can help manage water demand as well as provide an opportunity for funding mechanisms to continue expanding resiliency measures.

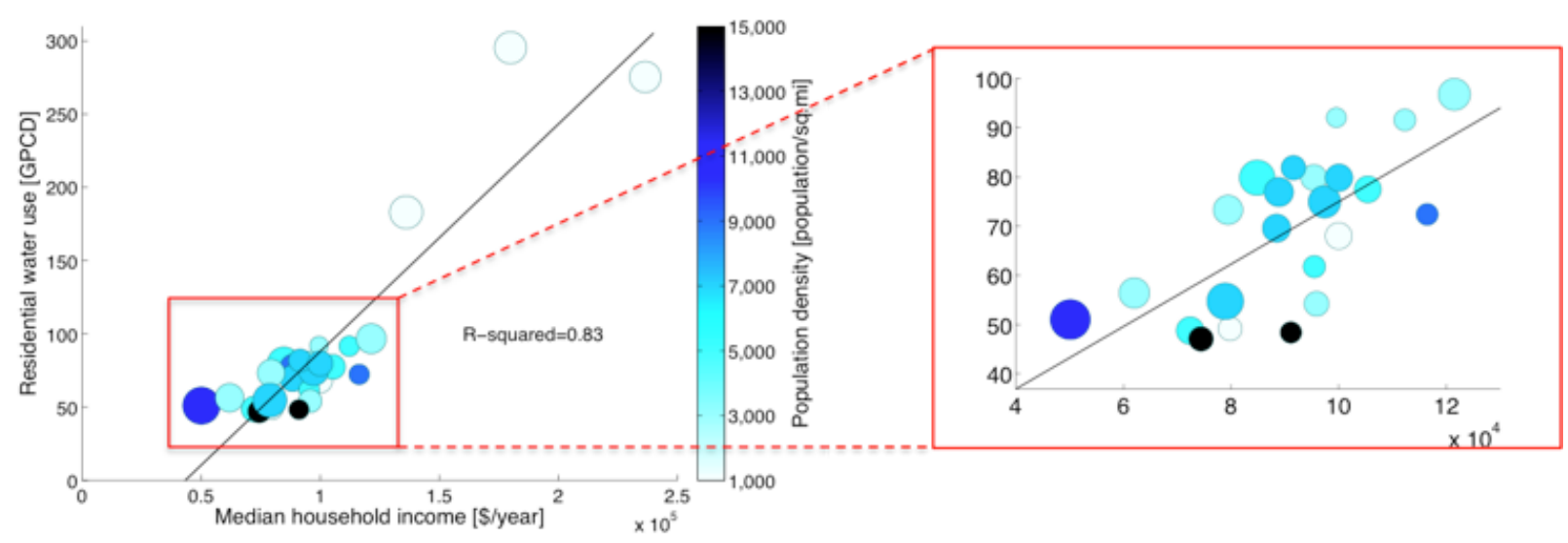


Figure 5. Linear regression of median household income (x-axis) on residential water use (y-axis). Relationship with water pricing (circle size) and population density (color scale) is also shown. Insert displays a closer look at the relationship when outliers are removed (corresponding to Hillsborough, Purissima Hills Water District, and CWS- Bear Gulch).

\subsubsection{Demand diversity}

Though BAWSCA serves mostly residential customers, other sectors including commercial, industrial, governmental uses, and dedicated irrigation account for $40 \%$ of the total water demand in the region. Having a diverse set of customers is important because using water in different demand sectors offers an opportunity to match alternative supply sources of different quality levels to non-potable uses [Hering et al., 2013]. These opportunities can be leveraged further through more efficient sharing of common resources. For example, the city of San Francisco has already established a program that promotes the development of in-building and district-scale, non-potable water reuse systems [SFPUC, 2015]. With this program, San Francisco provides small grants and technical assistance that incentivize new developments to be more selfreliant and to reduce their toll on high-quality water supplies where alternative sources may suffice. In our assessment, many BAWSCA utilities scored high in the demand diversity metric (Figure 3), indicating a capacity for similar programs.

\subsubsection{Adaptation capacity}

The adaptation capacity of a utility depends on technical and financial constraints, as well as the willingness of each service area to undertake new projects. As changing supply and demand dynamics affect people's perspectives on water use, the capacity to implement different conservation measures is also likely to evolve. For 
example, because of the ongoing drought, the state of California has issued executive orders to make water conservation a way of life extending beyond drought periods, and individual behavioral changes have contributed to decreasing water use in response to increased drought awareness [SWRCB, 2016]. For this study, the metrics shown in Figure 3 quantify the potential to conserve water and to augment supplies based on realistic projects self-reported by BAWSCA member agencies in recent studies [BAWSCA, 2014; BAWSCA, 2015b]. While many utilities may not have the capacity to implement significant adaptation strategies locally (e.g. small utilities such as Hillsborough have low scores in the adaptation metrics), there are opportunities for adaptation capacity projects in neighboring utilities and for regional-scale projects, all of which would reduce stress on existing supplies and enhance the reliability and resiliency of utilities small and large.

The diversity of supply and demand characteristics and existing agency interconnections within BAWSCA present several opportunities for the efficient implementation of additional conservation programs, supply augmentation, and targeting these projects to suit different demand sectors as discussed previously. For example, areas with low population density and low cost of land may be better equipped to implement new water infrastructure projects, while areas with higher water use and faster growth rates are the ones in greater need of securing new supplies. However, the locations of opportunity and need do not necessarily overlap. As BAWSCA agencies work on diversifying their supply portfolios, the existing infrastructure of the SF RWS is an opportunity for sharing these supplies, acting as a bank account. For example, many agencies are starting to outgrow their SF RWS allocations, whereas others like Palo 
Alto and Menlo Park have contracts for significantly more water than they are currently using (excess amounts that translate into 84 and 61 unused gallons per capita per day for these agencies, respectively) (Figure 4). This unused water remains in the SF RWS until claimed (assuming 100\% level of service). Given this discrepancy, the distribution of water supplies could be more effective through the development of flexible market mechanisms that take advantage of common supply pools [Anderson, 2015; Grafton et al., 2011; Palazzo and Brozovic, 2014; Stern, 2010]. This type of collaborative management solution is particularly relevant for BAWSCA given the existing overlap in natural resource and political boundaries among agencies, as well as established coordination layers.

\subsection{Responding to the drought}

\subsubsection{Local resilience}

BAWSCA water agencies, along with the rest of California, have been struggling with a severe drought from 2012 to 2015 and still ongoing. We applied our resilience framework to evaluate whether recent changes in water management and community behavior in response to the drought have resulted in enhanced resiliency and reliability. Figure 6 shows that overall utilities have made slight improvements in increasing their resilience metrics from fiscal year 2010-11 (prior to the drought) to 2014-15 (the fourth continuous drought year). The distributions of supply portfolios and demand sectors haven't changed much in this period, and utilities have not added significant new supply sources. Instead, the improvements observed from 2010-11 to 2014-15 are reflective of the emphasis on water efficiency and conservation in the region. This progress has not 
only demonstrated the capacity for demand-side management to create resiliency in the short-term, but also a potential for lowering demand in the long-term.

Many utilities also foresee the possibility to continue enhancing the observed resiliency moving forward (2014-15 + adaptation in Figure 6) by continuing to pursue conservation and augmentation projects as recently reported by BAWSCA [BAWSCA, 2014; BAWSCA, 2015a]. Potential augmentation projects included in this comparison include several recycled water projects, a groundwater project, local capture and reuse of rainwater, greywater and stormwater, desalination of bay water and brackish groundwater, and water transfers from other regions, all of which are being considered as part of BAWSCA's Long-Term Supply Reliability Strategy.

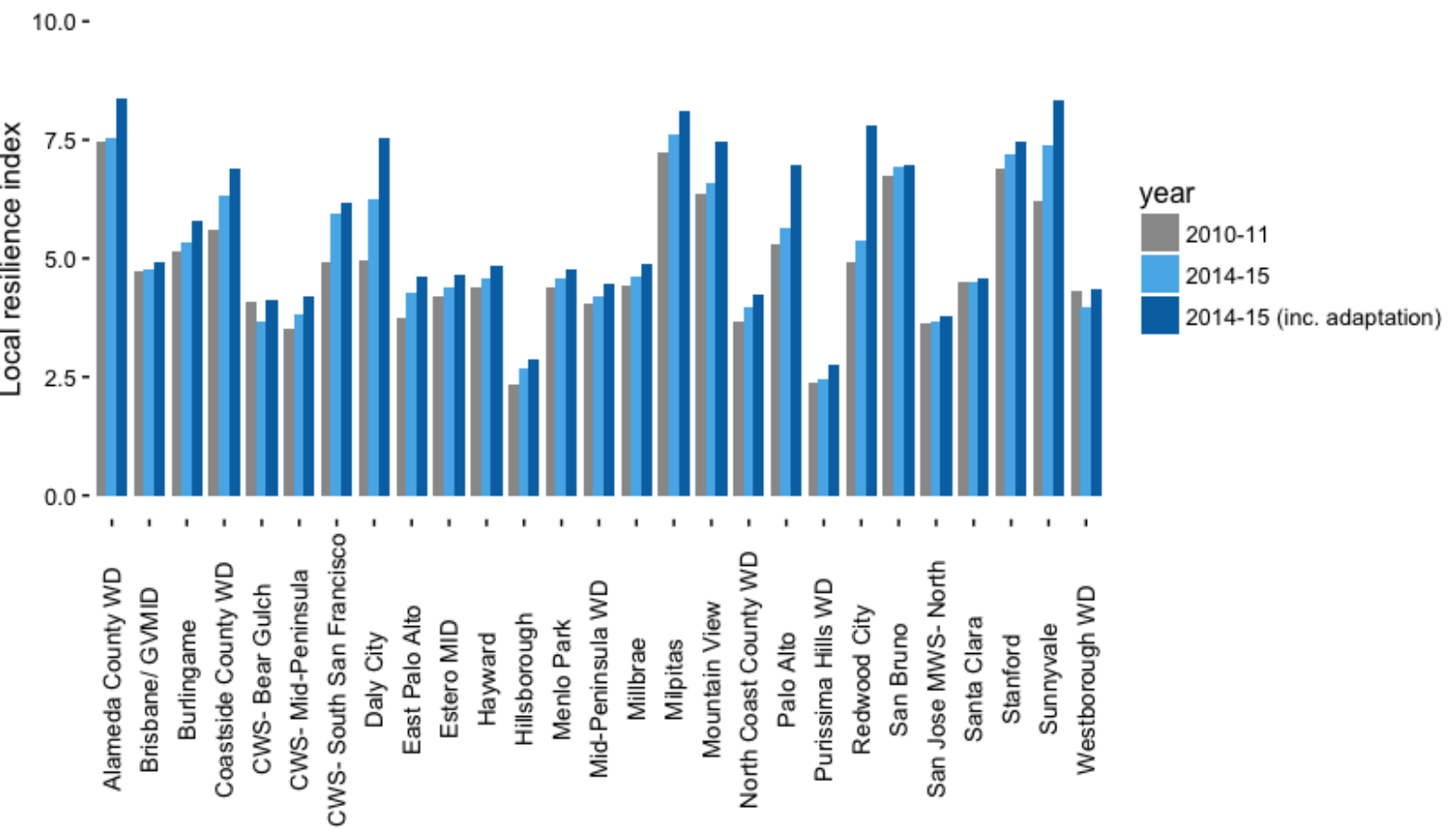

Agency

Figure 6. Change in local resilience index among BAWSCA member agencies. Bars show comparison between scores in fiscal year 2010-11, 2014-15, and potential resilience improvements with the addition of adaptation measures through conservation and supply augmentation projects.

\subsubsection{Regional resilience}


We explored the regional impacts of utilities' individual indicator performance by computing a BAWSCA-wide resilience index. Water utilities with low resilience scores are at high risk in terms of growth and the challenges of water shortage. While these utilities could improve their performance through independent supply augmentation and demand management efforts as shown in Figure 6, higher reliability and resilience could also be achieved through collaborations with neighboring utilities. For example, while the Town of Hillsborough has one of the lowest resilience indices in our framework, it only accounts for $1.5 \%$ of the total water use among the BAWSCA agencies, giving it some flexibility to share alternative supply projects with other small utilities or to negotiate small portions of a larger project.

For the purposes of regional integration, each component was calculated as a weighted average of individual utilities, with weights corresponding to water use. This reflects the fact that each water service provider acts as a small piece of a regional pool of water supplies and demands. Adaptation capacity scenarios were added as either agency-specific, in which case local resilience is directly enhanced and correspondingly weights into the resilience of the region, or regional projects meant to benefit BAWSCA as a whole. Figure 7 shows the performance of BAWSCA as a whole from fiscal year 2002-03 to 2014-15. The time series shows a steady, though very slow, increase in resilience over this period attributed mainly to water conservation and efficiency measures, as supply and demand portfolios have not changed significantly. This trend is particularly visible in the change between $2013-14$ and 2014-15, when water agencies in California started implementing significant conservation measures in response to the drought. 


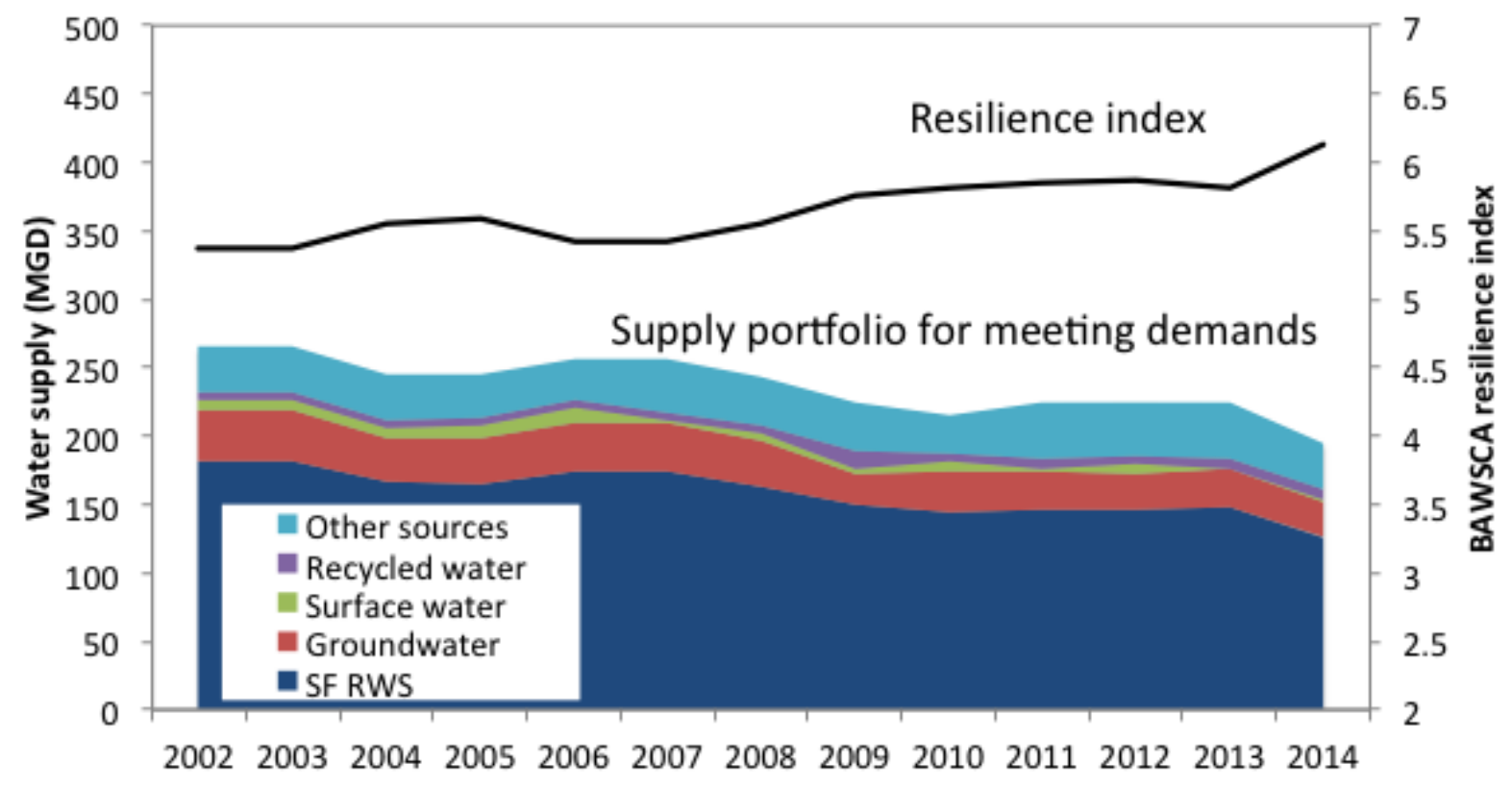

Figure 7. BAWSCA-wide resilience index and supply portfolios from fiscal year 2002-03 to 2014-15.

Using our framework, we compare this business-as-usual scenario to alternative cases that include adaptation capacity measures (Figure 8). There are clear performance benefits of including both local and regional supply augmentation and diversification projects, all of which can help reduce stress on existing supply sources and thus benefit agencies that rely on the same common pool of water resources. The regional resilience index has the potential to increase if all local and regional projects continue in the pipeline, while individual utilities could not reach this the same level of benefits independently. Moreover, the comparison of scenarios in Figure $\mathbf{8}$ allows us to visualize how sensitive each indicator is to changes in local and regional adaptation strategies. In this case, the metrics of supply stress and supply diversity show the highest sensitivity to additional adaptation capacity measures, reflective of the high dependency of the region on a single supply source and the considerable potential for enhancing resilience by focusing on these measures. 
These numbers are relative to the indicators and assumptions of this case study, and should be used only as a snapshot in time, to assess intra-regional decisions. The consideration of all these components in a systematic framework provides important insights for the region, integrating information available into the decision-making process at a level that decision-makers can understand, and preventing the loss of any relevant information. As the region progresses towards more reliable supplies and the priorities shift, the baseline metrics used for initial assessment may be adjusted and rescaled accordingly.

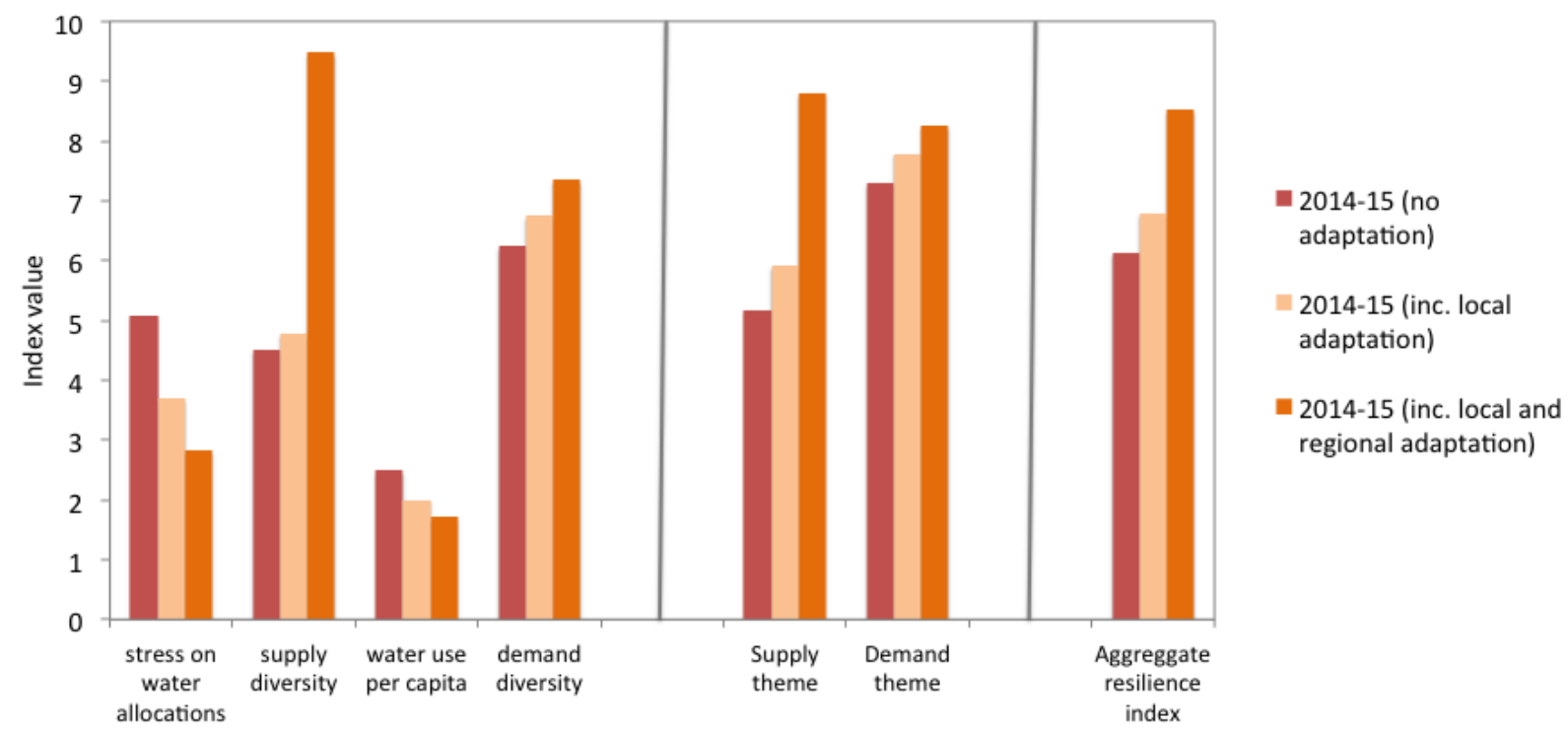

Figure 8 Regional resilience indicators under 2014-15 conditions, a local adaptation scenario, and a local + regional adaptation scenario.

\section{Conclusions}

Water shortages are a prevalent risk in many parts of the world as a result of a changing climate, rapidly growing populations, and over-reliance on imported supplies. Regional coordination, defined by common socio-hydrological water issues and opportunities as exemplified by our framework, can greatly contribute to better resource 
management, promote supply diversification, and help address the risks associated with water shortages. This work develops a generalized socio-hydrologic framework that can provide a platform for more holistic bottom-up assessments of urban water systems as these move from centralized to decentralized approaches. In this way, the framework can help decision-makers identify and evaluate solutions in order to enhance reliability and resilience, given the diversity of local and regional characteristics, criteria, and preferences.

The application of our integrative framework to the case study of the Bay Area Water Supply and Conservation Agency demonstrates how, rather than being competitors for a limited resource, interconnected utilities have the opportunity to be partners in a dynamic system of adaptation capacity building. While our framework helps assess the opportunities and potential impact of adaptation strategies, future work should also consider how to best guide the selection of these strategies among available options to make sure the strategies are feasible and sustainable in practice. For example, it is important to have a more diversified supply portfolio, but also to account for the cost, drought-proof, interdependency, and limitations of different supply sources. This study introduces an innovative approach to measure supply diversity, bringing the Gini-Simpson index, commonly used in diversity studies in other sectors, to the field of water management. This metric can be used as a first step in evaluating the resiliency of a region and the impacts of potential adaptation scenarios. Similar innovative metrics could be further adapted and added to our proposed framework to support decision-makers in the transition to a more holistic water management paradigm. More importantly, emerging decision-support tools should take into account 
bottom-up perspectives as identified in this work, and enable knowledge-sharing and collaboration in the pursue of more reliable and resilient water supplies.

\section{Acknowledgements}

This work was supported by the National Science Foundation (NSF) Engineering Research Center for Reinventing the Nation's Urban Water Infrastructure (ReNUWIt) EEC- 1028968, and an NSF Graduate Research Fellowship. We would like to thank Adrianne Carr, Michael Hurley, and Andree Johnson for providing us with constructive insights throughout this research. 


\section{References}

Ajami, N. K., Hornberger, G. M., and Sunding, D.L.: Sustainable water resource management under hydrological uncertainty, Water Resources Research, 44, W11406, doi: 10.1029/2007WR006736, 2008.

Anderson, T. L.: Dynamic Markets for Dynamic Environments: The Case for Water Marketing, Daedalus, 144, 83-93, 2015.

Arlosoroff, S.: Wastewater management, treatment, and reuse in Israel, Wastewater Reused - Risk Assessment, Decision-Making and Environmental Security, 55-64, 10.1007/978-1-4020-6027-4_6, 2007.

Aydin, N. Y., Zeckzer, D., Hagen, H., and Schmitt, T.: A decision support system for the technical sustainability assessment of water distribution systems, Environmental Modelling \& Software, 67, 31-42, 10.1016/j.envsoft.2015.01.006, 2015.

BAWSCA: Regional Water Demand and Conservation Projections, Bay Area Water Supply and Conservation Agency, Web site, available at: http://www.bawsca.org/docs/BAWSCA\%20Demand\%20and\%20Conservation\%2 OProjection\%20FINAL\%20REPORT.pdf, 2014.

BAWSCA: Annual Survey FY 2014-15, Bay Area Water Supply and Conservation Agency, Web site, available at: http://www.bawsca.org/docs/BAWSCA_FY1415_AnnualSurvey.pdf, 2015a.

BAWSCA: Long-Term Reliable Water Supply Strategy Phase II- Final Report. Bay Area Water Supply and Conservation Agency, Web site, available at: http://bawsca.org/water-supply/long-term-reliable-water-supply-strategy/, 2015b.

Beh, E. H. Y., Dandy, G. C., Maier, H. R., and Paton, F. L.: Optimal sequencing of water supply options at the regional scale incorporating alternative water supply sources and multiple objectives, Environ. Modell. Softw., 53, 137-153, 2014.

Beh, E. H. Y., Maier, H. R., and Dandy, G. C.: Adaptive, multiobjective optimal sequencing approach for urban water supply augmentation under deep uncertainty, Water Resources Research, 51, 1529-1551, 10.1002/2014wr016254, 2015.

Berkes, F.: Evolution of co-management: Role of knowledge generation, bridging organizations and social learning, J. Environ. Manage., 90, 1692-1702, 2009.

Brown, R. R., and Farrelly, M. A.: Delivering sustainable urban water management: a review of the hurdles we face, Water Science and Technology, 59, 839-846, 10.2166/wst.2009.028, 2009. 
Brown, C. M., Lund, J. R., Cai, X., Reed, P. M., Zagona, E. A., Ostfeld, A., Hall, J., Characklis, G. W., Yu, W., and Brekke, L.: The future of water resources systems analysis: toward a scientific framework for sustainable water management, Water Resour. Res., 51, 6110-6124, 2015.

Brozovic, N., Sunding, D. L., and Zilberman, D.: Estimating business and residential water supply interruption losses from catastrophic events, Water Resour. Res., 43, W08423, doi:10.1029/2005WR004782, 2007.

Cai, X. M., Lasdon, L., and Michelsen, A. M.: Group decision making in water resources planning using multiple objective analysis, J. Water Res. PI.-ASCE, 130, 4-14, 2004.

CA Water Code. Division 31: Bay Area Water Supply and Conservation Agency. Chapter 1. General provisions $\S 81301$.

CA Water Code. Division 35. Sacramento-San Joaquin Delta Reform Act of 2009. Chapter 2. Delta Policy $\S 85021$.

Carr, G., Bloeschl, G., and Loucks, D. P.: Evaluating participation in water resource management: a review, Water Resour. Res., 48, W11401, doi:10.1029/2011WR011662, 2012.

Cayan, D. R., Das, T., Pierce, D. W., Barnett, T. P., Tyree, M., and Gershunov, A.: Future dryness in the southwest US and the hydrology of the early 21st century drought, P. Natl. Acad. Sci. USA, 107, 21271-21276, 2010.

CDWR: California Water Plan Update 2013. Volume 1 - The Strategic Plan, California Department of Water Resources, Sacramento, CA, Web site, available at: http://www.waterplan.water.ca.gov/docs/cwpu2013/Final/0a-Vol1-full2.pdf, 2013.

CDWR: California's Most Significant Droughts: Comparing Historical and Recent Conditions, Report, available at: http://www.water.ca.gov/waterconditions/docs/California_Signficant_Droughts_20 15_small.pdf, 2015.

Chartres, C., and Williams, J.: Can Australia Overcome its Water Scarcity Problems?, Journal of Developments in Sustainable Agriculture, 1, 17-24, 2006.

Connell-Buck, C. R., Medellin-Azuara, J., Lund, J. R., and Madani, K.: Adapting California's water system to warm vs. dry climates, Climatic Change, 109, S133S149, 10.1007/s10584-011-0302-7, 2011.

Diffenbaugh, N. S., Swain, D. L., and Touma, D.: Anthropogenic warming has increased drought risk in California, P. Natl. Acad. Sci. USA, 112, 3931-3936, 2015.

Ferguson, B. C., Brown, R. R., Frantzeskaki, N., de Haan, F. J., and Deletic, A.: The enabling institutional context for integrated water management: Lessons from 
Melbourne, Water Research, 47, 7300-7314, 10.1016/j.watres.2013.09.045, 2013.

Fielding, K., Gardner, J., Leviston, Z., and Price, J.: Comparing public perceptions of alternative water wources for potable use: the case of rainwater, stormwater, desalinated water, and recycled water, Water Resour. Manag., 29, 4501-4518, 2015.

Galan, J. M., Lopez-Paredes, A., and del Olmo, R.: An agent-based model for domestic water management in Valladolid metropolitan area, Water Resour. Res., 45, W05401, doi:10.1029/2007WR006536, 2009.

Gibbs, J. P. and Martin, W. T.: Urbanization, technology, and the division of labor: international patterns, Am. Sociol. Rev., 27, 667-677, 1962.

Grafton, R. Q., Libecap, G., McGlennon, S., Landry, C., and O'Brien, B.: An integrated assessment of water markets: a cross-country comparison, Rev. Environ. Econom. Pol., 5, 219-239, 2011.

Grantham, T. E. and Viers, J. H.: 100 years of California's water rights system: patterns, trends and uncertainty, Environ. Res. Lett., 9, 084012, doi:10.1088/17489326/9/8/084012, 2014.

Graymore, M. L. M., Sipe, N. G., and Rickson, R. E.: Sustaining Human Carrying Capacity: A tool for regional sustainability assessment, Ecological Economics, 69, 459-468, 10.1016/j.ecolecon.2009.08.016, 2010.

Hashimoto, T., Stedinger, J. R., and Loucks, D. P.: Reliability, resiliency, and vulnerability criteria for water-resource system performance evaluation, Water Resources Research, 18, 14-20, 10.1029/WR018i001p00014, 1982.

Hering, J. G., Waite, T. D., Luthy, R. G., Drewes, J. E., and Sedlak, D. L.: A changing framework for urban water systems, Environ. Sci. Technol., 47, 10721-10726, 2013.

Hornberger, G. M., Hess, D. J., and Gilligan, J.: Water conservation and hydrological transitions in cities in the United States, Water Resour. Res., 51, 4635-4649, 2015.

Hughes, S.: Authority Structures and Service Reform in Multilevel Urban Governance: The Case of Wastewater Recycling in California and Australia, Urban Affairs Review, 49, 381-407, 10.1177/1078087412458762, 2013.

Hughes, S., Pincetl, S., and Boone, C.: Triple exposure: Regulatory, climatic, and political drivers of water management changes in the city of Los Angeles, Cities, 32, 51-59, 10.1016/j.cities.2013.02.007, 2013. 
Hughes, S. and Pincetl, S.: Evaluating collaborative institutions in context: the case of regional water management in southern California, Environ. Plann. C, 32, 20-38, 2014.

Humprecht, E., and Buechel, F.: More of the Same or Marketplace of Opinions? A Cross-National Comparison of Diversity in Online News Reporting, International Journal of Press-Politics, 18, 436-461, 10.1177/1940161213497595, 2013.

Hurlbert, S. H.: Nonconcept of species diversity - Critique and alternative parameters, Ecology, 52, 577-586, 10.2307/1934145, 1971.

Juwana, I., Muttil, N., and Perera, B. J. C.: Indicator-based water sustainability assessment - a review, Sci. Total Environ., 438, 357-371, 2012.

Kauffman, G. J.: What if... the United States of America were based on watersheds?, Water Policy, 4, 57-68, 2002.

Khater, M., Scawthorn, C., and Rojahn, C.: A model methodology for assessment of seismic vulnerability and impact of disruption of water supply systems, in Earthquake Hazard Reduction in the Central and Eastern Unites States: A Time for Examination and Action (Socioeconomic Impacts: 1993 National Earthquake Conference), edited by: Tierney, K. J. and Nigg, J. M., Cent. U.S. Earthquake Consortium, Memphis, Tenn., 605-614, 1993.

Kidson, R., Haddad, B., Zheng, H., Kasower, S., and Raucher, R.: Optimising Reliability: Portfolio Modeling of Contract Types for Retail Water Providers, Water Resources Management, 27, 3209-3225, 10.1007/s11269-013-0320-5, 2013.

$\mathrm{Li}, \mathrm{Y}$. , and Lence, B. J.: Estimating resilience for water resources systems, Water Resources Research, 43, 10.1029/2006wr005636, 2007.

Liu, D., Tian, F., Lin, M., and Sivapalan, M.: A conceptual socio-hydrological model of the co-evolution of humans and water: case study of the Tarim River basin, western China, Hydrol. Earth Syst. Sci., 19, 1035-1054, doi:10.519/hess-191035-2015, 2015.

Loch, A., Adamson, D., and Mallawaarachchi, T.: Role of hydrology and economics in water management policy under increasing uncertainty, J. Hydrol., 518, 5-16, 2014.

Loucks, D. P.: Quantifying trends in system sustainability, Hydrolog. Sci. J., 42, 513530, 1997.

Loucks, D. P.: Sustainable water resources management, Water Int., 25, 3-10, 2000.

Loucks, D. P.: Decision support systems for drought management, in: Drought Management and Planning for Water Resources, edited by: Vela, A., Rossi, G., Andreu, J., and Vagliasindi, F. CRC Press, 119-131, 2005. 
Luthy, R. G. and Sedlak, D. L.: Urban water-supply reinvention, Daedalus, 144, 72-82, 2015.

Marlow, D. R., Moglia, M., Cook, S., and Beale, D. J.: Towards sustainable urban water management: A critical reassessment, Water Research, 47, 7150-7161, 10.1016/j.watres.2013.07.046, 2013.

McDonald, D. G., and Dimmick, J.: The conceptualization and measurement of diversity, Communication Research, 30, 60-79, 10.1177/0093650202239026, 2003.

Milman, A. and Short, A.: Incorporating resilience into sustainability indicators: An example for the urban water sector, Global Environ. Chang., 18, 758-767, 2008.

Mini, C., Hogue, T. S., and Pincetl, S.: Patterns and controlling factors of residential water use in Los Angeles, California, Water Policy, 16, 1054-1069, 2014.

Mini, C., Hogue, T. S., and Pincetl, S.: The effectiveness of water conservation measures on summer residential water use in Los Angeles, California, Resour. Conserv. Recy., 94, 136-145, 2015.

Moglia, M., Alexander, K. S., and Sharma, A.: Discussion of the enabling environments for decentralised water systems, Water Science and Technology, 63, 2331-2339, 10.2166/wst.2011.443, 2011.

Morris, E. K., Caruso, T., Buscot, F., Fischer, M., Hancock, C., Maier, T. S., Meiners, T., Mueller, C., Obermaier, E., Prati, D., Socher, S. A., Sonnemann, I., Waeschke, N., Wubet, T., Wurst, S., and Rillig, M. C.: Choosing and using diversity indices: insights for ecological applications from the German Biodiversity Exploratories, Ecology and Evolution, 4, 3514-3524, 10.1002/ece3.1155, 2014.

Nelson, R., Howden, M., and Smith, M. S.: Using adaptive governance to rethink the way science supports Australian drought policy, Environmental Science \& Policy, 11, 588-601, 10.1016/j.envsci.2008.06.005, 2008.

Newman, J. P., Dandy, G. C., and Maier, H. R.: Multiobjective optimization of clusterscale urban water systems investigating alternative water sources and level of decentralization, Water Resour. Res., 50, 7915-7938, 2014.

Oksanen, J., Bergman, C., Sainio, J., and Westerholm, J.: Methods for deriving and calibrating privacy-preserving heat maps from mobile sports tracking application data, Journal of Transport Geography, 48, 135-144, 10.1016/j.jtrangeo.2015.09.001, 2015.

Pacific Institute: Water Rates: Water Affordability, Report., available at: http://www.pacinst.org/wp-content/uploads/2013/01/water-rates-affordability.pdf, 2013. 
Padowski, J. C. and Jawitz, J. W.: The future of global water scarcity: policy and management challenges and opportunities, The Whitehead Journal of Diplomacy and International Relations, 10, 99-114, 2009.

Padowski, J. C., and Gorelick, S. M.: Global analysis of urban surface water supply vulnerability, Environmental Research Letters, 9, 10.1088/17489326/9/10/104004, 2014.

Padowski, J. C., Gorelick, S. M. , Thompson, B. H., Rozelle, S. , and Fendorf, S.: Assessment of human-natural system characteristics influencing global freshwater supply vulnerability, Environmental Research Letters, 10, doi:10.1088/1748-9326/10/10/104014, 2015.

Palazzo, A., and Brozovic, N.: The role of groundwater trading in spatial water management, Agr. Water Manage., 145, 50-60, 2014.

Panagopoulos, G. P.: Assessing the impacts of socio-economic and hydrological factors on urban water demand: s multivariate statistical approach, J. Hydrol., 518, 4248, 2014.

Panniello, U., Tuzhilin, A., and Gorgoglione, M.: Comparing context-aware recommender systems in terms of accuracy and diversity, User Modeling and User-Adapted Interaction, 24, 35-65, 10.1007/s11257-012-9135-y, 2014.

Paton, F. L., Dandy, G. C., and Maier, H. R.: Integrated framework for assessing urban water supply security of systems with non-traditional sources under climate change, Environ. Modell. Softw., 60, 302-319, 2014.

Re, V.: Incorporating the social dimension into hydrogeochemical investigations for rural development: the Bir Al-Nas approach for socio-hydrogeology, Hydrogeol. J., 23, 1293-1304, 2015.

Rijke, J., Farrelly, M., Brown, R., and Zevenbergen, C.: Configuring transformative governance to enhance resilient urban water systems, Environmental Science \& Policy, 25, 62-72, 10.1016/j.envsci.2012.09.012, 2013.

Sandoval-Solis, S., McKinney, D. C., and Loucks, D. P.: Sustainability index for water resources planning and management, J. Water Res. PI.-ASCE, 137, 381-390, 2011.

SFPUC: 2013 Water Availability Study for the City and County of San Francisco, San Francisco Public Utilities Commission, 2013.

SFPUC: Non-Potable Water Program, San Francisco Public Utilities Commission, Web site, available at: http://www.sfwater.org/index.aspx?page=686, 2015.

Simpson, E. H.: Measurement of diversity, Nature, 163, 688-688, 1949. 
Sivapalan, M., Savenije, H. H. G., and Bloeschl, G.: Socio-hydrology: a new science of people and water, Hydrol. Process., 26, 1270-1276, 2012.

Sivapalan, M., Konar, M., Srinivasan, V., Chhatre, A., Wutich, A., Scott, C. A., Wescoat, J. L., and Rodriguez-Iturbe, I.: Socio-hydrology: use-inspired water sustainability science for the anthropocene, Earth's Future, 2, 225-230, 2014.

Srinivasan, V.: Reimagining the past - use of counterfactual trajectories in sociohydrological modelling: the case of Chennai, India, Hydrol. Earth Syst. Sci., 19, 785-801, doi:10.5194/hess-19-785-2015, 2015.

Srinivasan, V., Gorelick, S., and Goulder, L.: A hydrologic-economic modeling approach for analysis of urban water supply dynamics in Chennai, India, Water Resour. Res., 46, W07540, doi:10.1029/2009WR008693, 2010.

Srinivasan, V., Lambin, E. F., Gorelick, S. M., Thompson, B. H., and Rozelle, S.: The nature and causes of the global water crisis: syndromes from a meta-analysis of coupled human-water studies, Water Resour. Res., 48, W10515, doi:10.1029/2011WR011087, 2012.

Stern, J.: Introducing competition into England and Wales water industry - lessons from UK and EU energy market liberalisation, Utilities Policy, 18, 120-128, 2010.

Sullivan, C., Meigh, J., and Lawrence, P.: Application of the water poverty index at different scales: A cautionary tale, Water International, 31, 412-426, 2006.

SWRCB: State Water Resources Control Board Water Conservation Portal Emergency Conservation Regulation, State Water Resources Control Board, Web site, available at: http://www.waterboards.ca.gov/water_issues/programs/conservation_portal/emer gency_regulation.shtml, 2015.

Tal, A.: Seeking sustainability: Israel's evolving water management strategy, Science, 313, 1081-1084, 10.1126/science.1126011, 2006.

Tarroja, B., AghaKouchak, A., Sobhani, R., Feldman, D., Jiang, S., and Samuelsen, S.: Evaluating options for Balancing the water-electricity nexus in California: part 1securing water availability, Sci. Total Environ., 497, 697-710, 2014.

Thompson, S. E., Sivapalan, M., Harman, C. J., Srinivasan, V., Hipsey, M. R., Reed, P., Montanari, A., and Bloeschl, G.: Developing predictive insight into changing water systems: use-inspired hydrologic science for the anthropocene, Hydrol. Earth Syst. Sci., 17, 5013-5039, doi:10.5194/hess-17-5013-2013, 2013.

United States Census Bureau: American Community Survey 2013, Web site, available at: http://www.census.gov/, 2013. 
van Beers, C., and Zand, F.: R\&D Cooperation, Partner Diversity, and Innovation Performance: An Empirical Analysis, Journal of Product Innovation Management, 31, 292-312, 10.1111/jpim.12096, 2014.

Viviroli, D., Archer, D. R., Buytaert, W., Fowler, H. J., Greenwood, G. B., Hamlet, A. F., Huang, Y., Koboltschnig, G., Litaor, M. I., Lopez-Moreno, J. I., Lorentz, S., Schadler, B., Schreier, H., Schwaiger, K., Vuille, M., and Woods, R.: Climate change and mountain water resources: overview and recommendations for research, management and policy, Hydrol. Earth Syst. Sci., 15, 471-504, doi:10.5194/hess-15-471-2011, 2011.

Winz, I., Trowsdale, S., and Brierley, G.: Understanding barrier interactions to support the implementation of sustainable urban water management, Urban Water Journal, 11, 497-505, 10.1080/1573062x.2013.832777, 2014.

Zeff, H. B., Kasprzyk, J. R., Herman, J. D., Reed, P. M., and Characklis, G. W.: Navigating financial and supply reliability tradeoffs in regional drought management portfolios, Water Resources Research, 50, 4906-4923, 10.1002/2013wr015126, 2014. 